\title{
HA-1(H) Genotype Positive
}

National Cancer Institute

\section{Source}

National Cancer Institute. HA-1(H) Genotype Positive. NCI Thesaurus. Code C157564.

A genetic finding indicating that a subject expresses the $\mathrm{HA}-1(\mathrm{H})$ genotype and has a homozygous or heterozygous nucleotide substitution at position 416 of the ARHGAP45 gene where the guanine has been mutated to adenine, which encodes a variant of Rho GT Pase-activating protein 45 where the arginine at position 139 has been replaced by histidine. The HA-1(H) form of ARHGAP45 protein can be processed into a nonapeptide that can be presented by HLA-A*0201 and other HLA-A isoforms, while the peptide produced by processing the protein resulting from transcription of the ARHGAP45 gene with guanine at position 416, which will have arginine at amino acid residue 139 (HA-1(R)) cannot bind HLA-A. 